\title{
O Debate sobre a Homossexualidade Mediado por Representações Sociais: Perspectivas Homossexuais e Heterossexuais
}

\author{
The Debate on Homosexuality Mediated by Social Representations: \\ Homosexual and Heterosexual Perspectives
}

Anderson Scardua*, Edson Alves de Souza Filho

Universidade Federal do Rio de Janeiro, Rio de Janeiro, Brasil

\begin{abstract}
Resumo
O objetivo deste trabalho foi estudar as representações sociais da homossexualidade entre estudantes universitários, segundo orientação sexual e sexo. Foram aplicadas uma questão de associação livre sobre a palavra homossexualidade e outra sobre as possíveis causas da mesma, sendo os dados analisados segundo os princípios da análise de conteúdo. Houve diferenças significativas entre os grupos, possibilitando-nos encontrar diferentes maneiras de se compreender/lidar com a homossexualidade e enfrentar preconceitos/discriminações. Os homens homossexuais, procuraram justificar/legitimar publicamente (direitos, liberdade) a homossexualidade com o argumento/representação de que ela é incontrolável/natural, enquanto as mulheres homossexuais preferiram construir e aperfeiçoar contratos de interação no plano interpessoal (família, namoro) para obter reconhecimento social. Já os homens e mulheres heterossexuais, referindo-se muito à normatização e outros conteúdos que reforçam as convenções sociais indicaram menos possibilidade de reconhecimento da homossexualidade.
\end{abstract}

Palavras-chave: Homossexualidade; representações sociais; reconhecimento social; causalidade.

\begin{abstract}
The objective of this work was to study the social representations of homosexuality among college students, according to sexual orientation and sex. One free association question about the word homosexuality and another about is possible causes were answered. The data was analyzed according to the principles of content analysis. There were significant differences among the groups, allowing us to find out different ways of understanding/dealing with homosexuality and facing prejudice/discrimination. The homosexual men publicly justified/legitimated (rights, freedom) homosexuality with the argument/representation that it is uncontrollable/ natural, while the homosexual women preferred to build and improve interaction agreements on the interpersonal level (family, love affair) to obtain social recognition. Yet the heterosexual men and women, with many references to normality and others contents that reinforce the social conventions, pointed out less possibility of recognition towards homosexuality.

Keywords: Homosexuality; social representations; social recognition; causality.
\end{abstract}

Muitas questões se colocam para os pesquisadores envolvidos com estudos relativos à homossexualidade. Há uma grande diversidade na forma de se conceber a mesma tanto no discurso acadêmico quanto no senso comum. Apesar desta dificuldade conceitual, sabemos existir uma esfera de intercâmbio e debate intra e intergrupal a respeito da homossexualidade que modifica e/ou fixa certas realidades sociais. Ou seja, supomos existir um "diálogo surdo" de participantes, que muitas vezes pretendem ignorar-se mutuamente, o que faz com que boa parte do que se diz sobre o assunto tenda a manifestar-se por meio de pares antitéticos, como afirmações e negações, prazeres e desprazeres, satisfações e insatisfações, entre outros tipos de elaborações psicossociais a serem melhor investigada.

Neste sentido, acreditamos ser necessários ouvir indivíduos e grupos para poder compreender o que eles entendem

\footnotetext{
* Endereço para correspondência: Estrada Rio Jequiá, 486/303, Zumbi, Rio de Janeiro, RJ, 21930-007. E-mail: andersonscardua@gmail.com
}

por homossexualidade. Muito além da esfera conceitual há um conhecimento compartilhado socialmente sobre este tema, que possibilita práticas entre indivíduos e grupos. Ou seja, tomamos como base a noção de que a homossexualidade é construída socialmente e só pode ser entendida dentro de um contexto social e histórico dinâmico. Tal multigrupalidade existente nas sociedades contemporâneas engendra múltiplas formas de ser, ver, compreender, representar, praticar, comunicar, vivenciar, enfim, debater a homossexualidade. Desta forma, utilizamos o referencial teórico das representações sociais de Moscovici $(1978,2003)$ para comparar grupos segundo orientação sexual e sexo.

Uma das principais preocupações de Moscovici ao desenvolver a teoria das representações sociais foi equacionar o modo como as sociedades recebem e transformam o saber científico, cuja presença cada vez maior causava então grande impacto social. Ele se interessava em como este conhecimento afetava a cultura e como ele era absorvido pelo discurso leigo (Moscovici, 2003). Contudo, a noção de 
representações sociais acabou servindo também de base para a descrição e explicação de conhecimento social elaborado e difundido para lidar com assuntos, eventos, indivíduos e grupos, que não se ajustam aos padrões culturais dos grupos mais numerosos, ou seja, o que é considerado estranho, indefinido ou incontrolável, como a homossexualidade.

As representações sociais são uma organização de opiniões, atitudes, crenças e informações determinadas pelos sujeitos, seu contex to e seus vínculos (Abric, 2001). Esta teoria parte da idéia de que os grupos e as sociedades têm conhecimentos compartilhados sobre a realidade que os circundam, que podem engendrar práticas e atitudes em relação aos mesmos. Elas permitem compreender de que forma um fenômeno se insere numa sociedade, a forma pela qual ele é entendido, comunicado, explicado, relacionado a forma como se age em relação a ele. Desta forma, segundo Moscovici (1978) uma das funções das representações sociais seria a de elaborar comportamentos e comunicações entre indivíduos, além de ressaltar a tendência das representações sociais em transformar algo não-familiar em familiar.

O conceito de representações sociais provém da definição de representações coletivas de Durkheim. Contudo, segundo Moscovici (1978) a noção de representações coletivas de Durkheim referia-se a um pensamento coletivo de sociedades pouco dinâmicas em que as interações intergrupais tinham pouca influência na elaboração de representações. Já as representações sociais são um fenômeno de sociedades modernas que apresentam um ambiente mais ativo de interações entre diferentes grupos, cada vez mais consolidados, emancipados e diferenciados para se articular, absorver e constituir os fenômenos sociais (Moscovici, 1978).

Há dois processos principais, de acordo com Jodelet (1986), referentes à construção da representação social. São eles a objetivação e a ancoragem. O primeiro refere-se ao processo de transformação do objeto da representação em algo objetivo, ou seja, passa do abstrato para o concreto. Segundo Jodelet, este processo ocorre através das seguintes fases: (a) seleção e descontex tualização, quando as informações relacionadas a um objeto de representação são escolhidas e utilizadas em função de critérios culturais e normativos dos grupos/indivíduos; (b) formação de um "núcleo figurativo", quando se dá a reprodução de uma estrutura conceitual a partir de uma estrutura imaginante visível; e (c) a naturalização, quando ocorre a atribuição de qualidade da natureza aos elementos do núcleo figurativo, como se tivessem vida própria.

Já a ancoragem, refere-se à inserção da representação e do seu objeto no social, ou seja, se refere à forma como um conhecimento se insere no pensamento pré-existente. Neste processo, ainda segundo Jodelet (1986), significação e utilidade são conferidas à representação social em relação ao seu objeto. Trata-se de produzir um conhecimento para os fins práticos de cada sujeito social, tais como influenciar, sobreviver, entre outros

Vale ainda ressaltar uma noção básica relacionada à representação que é o fato de toda representação ser uma representação de alguma coisa e de alguém. No caso de repre- sentações sociais, portanto, estas são produzidas por grupos sociais específicos, com características próprias. Apesar disso, Potter e Litton (1985) ressaltaram que muitas pesquisas em representações sociais preocuparam-se pouco com a definição e caracterização dos grupos estudados. Além disso, este pressuposto implica que nem todo o fenômeno ou objeto possui uma representação para todos os grupos sociais. Contudo, é de se esperar que muitos assuntos acabem sendo relevantes para mais de um grupo social, tornando necessário um recorte multigrupal e, mesmo, intergrupal para uma analise mais completa de suas representações sociais, uma vez que estas são formadas num campo de interações sociais, explícitas ou implícitas, em que as representações de um grupo, por mais invisível que este seja, acabam gerando reações e contra-reações em outros grupos/sujeitos sociais.

As questões concernentes à identidade sexual e ao desejo vêm sendo tratadas como algo relativo e como possíveis formas de contestação às normas socioculturais estabelecidas e rígidas. Elas estão sendo vistas como construções sociais e não algo natural e estável, como sendo produzidas, reproduzidas e constantemente repetidas nas relações e discursos sociais e como sendo experiências complexas não redutíveis a modelos simples (Adelman, 2000; Louro, 2001 ), apontando para a pluralidade do fenômeno da homossexualidade. Neste contexto, a emergência de um debate público sobre a homossexualidade reflete tanto a defesa quanto o combate da mesma. Historicamente, os argumentos propostos, sobretudo contra a prática e a difusão da homossexualidade, têm uma origem mais remota, enquanto os a favor mais recente. Contudo, a visibilidade da homossexualidade afirmativa, através de qualquer linguagem, ainda constitui-se em algo perturbador na sociedade gerando rigidez de ambas as partes, devido à dificuldade de negociação.

Desta forma, há muitas formas de se entender e vivenciar a homossexualidade e há uma gama enorme de comportamentos homoeróticos, porém muitos não identificam determinadas práticas deste tipo como caracterizando uma relação homossexual e/ou entre dois homossexuais. Isto depende da forma como a homossexualidade é representada em seu grupo social (cf. Green, 2000; Trevisan, 2000). Parte deste fenômeno deriva do fato histórico de as experiências homossexuais serem vividas mais no espaço privado, diminuindo as chances de reconhecimento social das mesmas, o que implica em uma menor consolidação no espaço público de um conhecimento mais favorável a respeito da homossexualidade. Ou seja, apesar da proliferação de espaços de "tolerância homossexual" em vários lugares do mundo nas últimas décadas e de algumas conquistas legislativas, esta situação não foi capaz de alterar significativamente concepções desfavoráveis e limitadas sobre homossexualidade que continuam sendo difundidas na sociedade. Neste sentido, Hubbard (2001) discute a relação entre cidadania e espaços sexuais público e privado, apontando que apesar de as minorias sexuais participarem mais do espaço público hoje em dia, elas ainda não atingiram uma cidadania. Além disso, este espaço público pode ser visto como uma ampliação 
da guetificação homossexual, onde o espaço para os homossexuais pode ser controlado (Trevisan, 2000).

Segundo Green (2000), no Brasil houve uma prevalência da visão heteronormativa dos papéis de gênero nos estudos sobre a homossexualidade. Só em 1958 concebeu-se a primeira definição dos homossexuais como um grupo minoritário com uma subcultura própria, diferenciando-se das definições patologizantes da época no Brasil. Já dentro da Psicologia, prevalecem estudos relacionados à atitudes e preconceitos referentes aos homossexuais, havendo ainda poucos trabalhos sobre a compreensão dos mesmos de forma afirmativa, autônoma e positiva.

Dentro da Medicina e Psicologia ainda pode-se verificar que a homossexualidade foi tratada como patologia até muito recentemente. O Conselho Federal de Medicina apenas em 1985 passou a não considerar a homossexualidade como doença, enquanto o Conselho Federal de Psicologia (CEP) e outras entidades de psicologia não se manifestaram a este respeito até mais recentemente. Mesmo que em 1975 a Associação Americana de Psicologia já tenha situado a homossexualidade dentro das orientações sexuais e não entre os distúrbios e doenças psicológicas, só em 1999 foi promulgada a resolução 001 , que estabelece aos psicólogos normas de atuação em relação às orientações sexuais, em que a homossexualidade não é considerada doença, nem distúrbio e os psicólogos não podem trabalhar em propostas de tratamento e de cura da mesma (Lacerda, Pereira \& Camino, 2002).

Sabemos que no senso comum existem esforços de explicação da homossexualidade, os quais foram observados por alguns estudiosos, tais como o trabalho de Lacerda, Pereira e Camino (2002), que buscou relacionar as formas de expressão de preconceito com as explicações sobre a homossexualidade. Os autores apresentaram aos participantes uma escala com cinco tipos distintos de possíveis explicações: religiosas; ético-morais; biológicas; psicológicas; e psicossociais. Apenas nesta última explicação havia respostas não tratando a homossexualidade como um problema e/ou falta.

Em um estudo sobre teorias leigas sobre os homossexuais, Furnham e Taylor (1990) ressaltaram os aspectos da etiologia, comportamentos e "curas" para a homossexualidade masculina. Segundo as suas conclusões, as pessoas do sexo feminino, com nível educacional alto, homossexuais e que têm um forte contato com os mesmos, tenderam a ter atitudes menos preconceituosas. Os principais fatores relativos à etiologia da homossexualidade foram: relações homossexuais precoces, genético, problemas paternos, medo de mulheres, doença mental e abuso sexual.

Deve-se ressaltar que em ambos os estudos acima mencionados (Furnahm \& Taylor, 1990; Lacerda, Pereira \& Camino, 2002), os autores apresentaram previamente uma lista para que os pesquisados avaliassem, havendo uma prevalência de respostas ligando a homossexualidade a um problema e/ou falta. Desta forma, houve nesses estudos menor possibilidade de observar e verificar uma variabilidade maior de formas de representação da homossexualidade inclusive positivas e afirmativas.
Entre os estudos de representações sociais, pode-se citar mais dois trabalhos sobre a homossexualidade, ambos de Ribeiro e Almeida (2003a, 2003b). O diferencial destes estudos é que eles não se limitaram a simples representação da homossexualidade, mas possibilitaram pensar numa psicologia dos grupos gay e lésbico. Ambos os estudos foram feitos apenas entre homossexuais, homens e mulheres. $\mathrm{O}$ primeiro deles buscou identificar as representações dos próprios gays e lésbicas. Foi elaborada uma entrevista semiestruturada, abarcando temas de definição e origem da homossexualidade, relação interpessoal (familiar, social e afetivo-amorosa) e preconceitos. Os principais resultados foram os seguintes: (a) os espaços de interações sociais para os homossexuais têm papel importante para a construção de relações afetivas e de identidade homossexual; (b) não houve consenso sobre as origens da homossexualidade, porém consideram-na um fenômeno normal; e (c) homens e mulheres homossexuais assumem e enfrentam o preconceito de formas diferentes, os primeiros buscam uma aceitação mais em âmbitos públicos, enquanto as últimas procuram aceitação na família. Já o segundo estudo buscou identificar quem são os homossexuais que falam sobre a violência sofrida e o que os mesmos dizem sobre ela. Para isto utilizaram fichas de atendimento de um programa de tele-atendimento de denúncia de violência contra homossexuais. Os principais resultados foram os seguintes: (a) os homossexuais que buscam dar visibilidade para suas vivências são jovens, do sexo masculino, gays e com escolaridade média; (b) as principais demandas feitas pelos participantes foram a descrição de violência e o sofrimento dela decorrente, assim como a busca de estratégias de enfrentamento da violência e a busca de informações sobre o programa; (c) a variável orientação sexual e sexo influi no que os homossexuais dizem sobre a violência vivida: os homens ressaltaram o enfrentamento da violência no espaço público, enquanto as mulheres descreveram o seu sofrimento no âmbito familiar. Com estes dados, os autores concluíram que os homossexuais homens têm papel importante no movimento homossexual, já que são eles que buscam dar visibilidade ao grupo, quebrar os silêncios e enfrentar publicamente a violência sofrida.

A partir destas noções, foi necessário delimitarmos um grupo específico para se estudar as representações sociais na homossexualidade e não nos equivocarmos em generalizações improdutivas. No caso, o grupo foi o de universitários da região metropolitana do Rio de Janeiro dividida segundo orientação sexual em homossexuais e heterossexuais, masculinos e femininos. Nossa hipótese foi que há diferenciação nas representações sociais da homossexualidade entre estes grupos.

\section{Método}

Fizeram parte da pesquisa 350 participantes. Todos eram estudantes universitários da cidade do Rio de Janeiro. Duzentos e onze destes se autodefiniram heterossexuais (HTs), dentre os quais 103 eram homens e 108 mulheres, com respectivas médias de idade de 21,44 e 21,31 . Cento e trinta e nove se autodefiniram como homossexuais (HM) ou 
bissexuais, dentre os quais 89 eram homens e 50 mulheres, com respectivas médias de idades 23,02 e 21,56 . Cabe ressaltar que os bissexuais foram reunidos aos homossexuais, já que o importante para a pesquisa era o assumir a vivência homossexual independente de ela ser exclusiva ou não. Os participantes auto-denominaram suas religiões da seguinte forma: as mulheres $\mathrm{HT}^{1}$ como, católicas (40), não disseram (24), espíritas (14), não têm (13), outros (17); os homens HT como, não disseram (33), católicos (30), não tem (13), ateu e cristão (5 cada), outros (17); as mulheres HM como, católicas (16), não têm e não disseram ( 8 cada), espírita (5), outros (13); por fim, os homens HM como, católicos (28), não tem (19), espírita (11) não disse (6), outros (25).

Foi aplicado um questionário que abarcava uma questão de associação livre sobre a palavra homossexualidade e outra, aberta, relativa às possíveis causas da mesma. Ainda houve questões sobre variáveis sociodemográficas, como sexo, idade, orientação sexual, entre outros. Os participantes responderam o questionário em suas universidades ou através da internet, em salas de bate-papo, entre os quais 12 eram homens HT, 9 mulheres HT, 36 mulheres HM e 80 homens HM. Neste último caso, após a entrada em salas de bate-papo voltadas para o público HM, foi afirmada a manutenção de anonimato e privacidade e solicitado aos que encaixassem na pesquisa e quisessem colaborar que se pronunciassem, ocasião em que as perguntas foram feitas e respondidas.

As respostas dos participantes foram analisadas através da análise de conteúdo temática, segundo os princípios de Bardin (1977). Os resultados foram distribuídos em tabelas que os relacionam com os grupos segundo as variáveis orientações sexuais e sexo. Para se verificar a significação estatística entre as comparações foi utilizado o teste do qui-quadrado através do programa Bioestat 2.0. Foram sublinhadas as diferenças de percentagens de temas entre os grupos acima de $25 \%$, indicando diferenciação intergrupal significativa.

\section{Resultados}

As categorias temáticas referentes às respostas às questões de associação livre e à questão sobre as possíveis causas homossexualidade estão descritas e exemplificadas abaixo e, posteriormente, foram dispostas em tabelas de freqüência e percentagem para comparação entre grupos:

\section{Definições da Homossexualidade}

Englobam respostas que remetem às possíveis definições e/ou causa da homossexualidade. Estas foram divididas em três grupos: Com intenção, que implica uma intencionalidade das pessoas em viverem a homossexualidade: opção, escolha, curiosidade, interesse; Sem intenção, que engloba respostas que apontam causas não intencionais para a homossexualidade: desejo, orientação, amor, atração; e, por último, os conteúdos que relacionam a homossexualidade a um problema

\footnotetext{
1 As palavras heterossexual, homossexual e suas formas plurais poderão ser substituídas ao longo do restante do texto pelas abreviações HT e HM, respectivamente.
}

psicológico e/ou biológico e/ou uma falta (doença, carência, problema genético, desvio de comportamento).

\section{Reconhecimento $(R)$}

Refere-se, em geral, a um pensamento positivo da homossexualidade e foi dividido em três tipos: Pessoal/privado de si e dos outros, que refere-se às resposta de auto-reconhecimento enquanto homossexuais ou a conteúdos que referiram-se às vivências deste tipo e que pudessem ser reconhecidos por outros grupos: orgulho, eu, minha vida, coragem, assumir; já o Interpessoal, implica em um reconhecimento das relações mantidas em grupos pequenos e da relação que o próprio sujeito tem com homossexuais: amigos, casais, carinho, relação, namorado(a), sexo; e o Público, que implica em um reconhecimento em esfera pública da homossexualidade, tanto em termos de seus direitos quanto em termos de símbolos que representam os homossexuais: direitos, dignidade, respeito, liberdade, locais para HM, artistas relacionados aos homossexuais.

\section{Referência à Discriminação e Preconceitos Sofridos (Ref. dis/ pre. sofridos)}

Refere-se a termos que apontam a vivência dos homossexuais de discriminação, preconceito e não reconhecimento social: preconceito, discriminação, marginalização, desrespeito, proibido.

\section{Conteúdos Agressivos}

Refere-se a termos que são ofensivos aos homossexuais: viado, sapatão, mutante, ridículo, feio, ódio, safadeza.

\section{Normatização}

Abarca respostas que fazem referência a algum tipo de norma social e convenção, além de aspectos de alteridade e de naturalização: normal, anormal, diferente, igual, natural, padronização, fora dos padrões de Deus.

\section{Características de Gênero}

Refere-se a temas relacionados a papeis/padrões de gênero masculino e feminino, como: masculinos, femininos, florzinha, afetação, virilidade, drag.

\section{Aspectos Sócio-Morais de Grupo (ASMG)}

São temas que indicam características sociais e morais atribuídas aos homossexuais. Foram divididos em dois subgrupos: negativos: futilidade, promiscuidade, drogas, aids, falsidade, vulgaridade; e positivos: alegria, fidelidade, sinceridade, felizes, determinação, tranqüilidade.

\section{Efeitos Sociais/Vivências Negativas de Si e dos Outros (ESVN)}

Refere-se a termos que apontam para uma vivência negatividade internalizada da homossexualidade por uma pessoa: frustração, humilhação, vergonha, medo, dúvida, baixa estima.

\section{Afirmação (Af.) da Identidade Heterossexual(HT)}

Engloba evocações que indicam a necessidade de uma afirmação da própria heterossexualidade ou um 
distanciamento mantido em relação aos homossexuais: não sou, opção que não é a minha, algo que não gostaria de ser, contanto que não me incomodem.

\section{Causas Naturais}

São conteúdos que relacionam a homossexualidade a uma naturalização ou ao âmbito das características inatas, que não impliquem em um problema: nasce assim, é da natureza da pessoa, é genético.

\section{Influências Sociais Gerais}

Refere-se a conteúdos que colocam a homossexualidade como decorrente de fatores sociais e/ou da interação com estes: companhias, ausências de pais, educação recebida, meio de convivência.

\section{Negação de Casualidade}

Abarca conteúdos que se referem à não existência de casualidade específicas e gerais para a homossexualidade e os conteúdos que afirmem que a mesma não se deve a determinados aspectos: nada, apenas se é assim, não é genético, não é influência.

\section{Assumir-se/Descobrir-se}

São conteúdos que ressaltam a homossexualidade como uma característica que descobre-se em si e assume-se: descobre-se com o tempo, mais cedo ou mais tarde se percebe como homossexual, assumir-se.

\section{Interação de Fatores Biológicos e Sociais}

São respostas que apontam a homossexualidade como resultante da interação destes dois fatores, como: genética mais o meio de convivência, biológico mais social, uma predisposição que pode ser desenvolvida com o meio social.

\section{Decepção/Não Satisfação como Sexo Oposto}

Refere-se a conteúdos que colocam a homossexualidade como decorrentes de más experiências em relações com pessoas do sexo oposto ou com a falta deste tipo de experiência: no meu caso foi decepção com os homens, falta de conhecimento do sexo oposto.

\section{Busca de Realização Pessoal}

Refere-se à homossexualidade como uma busca por realização pessoal, por felicidade ou por um sentir-se bem consigo mesmo.

\section{Várias Causas}

Engloba respostas que enfatizam uma variabilidade de causa para a homossexualidade: várias causas, cada caso é um caso, tendências mais o meio, mais a educação e mais uma escolha própria.

\section{Atração pelo Proibido/Protesto ao Convencional}

Refere-se à vontade de alguém ir contra a norma como fator decisivo de ser HM: querer ser diferente, atração pelo proibido, protesto.

\section{Desenvolvimento Psicológico el ou Biológico}

Engloba respostas que associam a homossexualidade com determinados períodos do desenvolvimento pessoal de cada um, como: não saber lidar com as mudanças do corpo na puberdade, algo que ocorre na infância, ter tido primeiras experiência sexuais com pessoas do mesmo sexo.

Pode se observar na Tabela 1, primeiramente, uma grande diferenciação entre os grupos na forma de representar as causas da homossexualidade. Enquanto os HT enfatizaram aspectos de intencionalidade na vivência da homossexualidade, os HM ressaltaram a não intencionalidade da mesma.

Tabela 1

Freqüências e Percentagens Referentes à Questão de Associação Livre

\begin{tabular}{|c|c|c|c|c|c|c|c|c|c|c|c|c|}
\hline \multirow{2}{*}{ Categorias/grupos } & \multicolumn{2}{|c|}{ homem HM } & \multicolumn{2}{|c|}{ mulher HM } & \multicolumn{2}{|c|}{ homem HT } & \multicolumn{2}{|c|}{ mulher HT } & \multicolumn{2}{|c|}{ total HM } & \multicolumn{2}{|c|}{ total HT } \\
\hline & $\mathrm{F}$ & $\%$ & F & $\%$ & $\mathrm{~F}$ & $\%$ & $\mathrm{~F}$ & $\%$ & $\mathrm{~F}$ & $\%$ & $\mathrm{~F}$ & $\%$ \\
\hline Com intenção & 13 & 4,0 & 07 & 3,8 & 36 & 10,3 & 53 & $\underline{14,4}$ & 20 & 3,9 & 89 & $\underline{12,4}$ \\
\hline Sem intenção & 55 & 17,0 & 34 & 18,8 & 10 & 2,8 & 17 & $\underline{4,6}$ & 89 & $\underline{17,6}$ & 27 & 3,7 \\
\hline Problema/falta & 05 & 1,5 & 02 & 1,1 & 16 & $\underline{4,5}$ & 11 & 2,9 & 07 & 1,3 & 27 & $\underline{3,7}$ \\
\hline R. pessoal & 21 & 6,5 & 11 & 6,1 & 11 & 3,1 & 16 & 4,3 & 32 & $\underline{6,3}$ & 27 & 3,7 \\
\hline R. interpessoal & 49 & 15,1 & 45 & $\underline{25,0}$ & 33 & 9,4 & 46 & 12,5 & 94 & $\underline{18,6}$ & 79 & 11,0 \\
\hline R. público & 48 & 14,8 & 20 & 11,1 & 49 & 14,0 & 52 & 14,1 & 68 & 13,5 & 101 & 14,1 \\
\hline Ref. Dis./pre. sofridos & 58 & 17,9 & 33 & 18,3 & 63 & 18,0 & 82 & 22,3 & 91 & 18,0 & 145 & 20,2 \\
\hline Normatização & 18 & 5,5 & 14 & 7,7 & 56 & $\underline{16,0}$ & 34 & 9,2 & 32 & 6,3 & 90 & $\underline{12,5}$ \\
\hline Temas agressivo & 08 & $\underline{2,5}$ & 02 & 1,1 & 29 & $\underline{8,3}$ & 07 & 1,9 & 10 & 1,9 & 36 & $\underline{5,0}$ \\
\hline Af. da identidade HT & 0 & 0 & 0 & 0 & 18 & $\underline{5,1}$ & 11 & 2,9 & 0 & 0 & 29 & $\underline{4,0}$ \\
\hline ASMG negativos & 16 & $\underline{4,9}$ & 01 & 0,5 & 10 & 2,8 & 10 & 2,7 & 17 & 3,3 & 20 & 2,7 \\
\hline ASMG positivos & 09 & 2,7 & 05 & 2,7 & 05 & 1,4 & 13 & $\underline{3,5}$ & 14 & 2,7 & 18 & 2,5 \\
\hline ESVN & 19 & $\underline{5,9}$ & 03 & 1,6 & 06 & 1,7 & 08 & 2,1 & 22 & $\underline{4,4}$ & 14 & 1,9 \\
\hline Características de gênero & 04 & 1,2 & 03 & 1,6 & 07 & 2,0 & 07 & 1,9 & 07 & 1,3 & 14 & 1,9 \\
\hline
\end{tabular}

Notas: Foram sublinhadas as diferenças mais importantes de percentagens de temas entre os grupos acima de $25 \%$.

$\chi^{2}=21,037, \mathrm{gl}=12, \mathrm{p}<0,0498$ para comparação entre homens e mulheres $\mathrm{HM} ; \chi^{2}=35,555, \mathrm{gl}=13, \mathrm{p}<0,0007$ para comparação entre homens e mulheres HT; $\chi^{2}=152,672, \mathrm{gl}=13, \mathrm{p}<0$,0000 para comparação entre total de HM e HT. 
Os primeiros, principalmente os homens, ainda tenderam a descrever a homossexualidade como um problema/falta.

Em relação ao reconhecimento da homossexualidade, pôde-se notar uma diferença quanto aos âmbitos pessoal e interpessoal, que foram mais ressaltados pelos HM. Contudo, em relação ao âmbito público houve uma aproximação entre os dois grupos. Entre os HM, as mulheres tenderam a ressaltar muito mais o reconhecimento interpessoal, enquanto os homens destacaram mais o aspecto público. Já entre os HT, os homens e mulheres aproximam-se aos últimos, apresentando uma leve inclinação para o reconhecimento público.

Os HT, principalmente os homens, evocaram mais temas agressivos, além de ressaltarem em maior quantidade os aspectos de normatização e afirmação da identidade HT. Já as mulheres, comparadas aos homens, falaram mais em características sócio-morais positivas, porém, elas também apresentaram uma quantidade próxima de conteúdos referentes às características sócio-morais negativas, mostrando ambivalências nestes aspectos.

Já entre os HM, os homens tenderam a ressaltar mais os aspectos sócio-morais de grupos negativos, as vivências e os efeitos sociais negativos pelos quais passam e os temas agressivos. Os aspectos sócio-morais positivos e as características de gênero foram evocados em quantidade próxima por ambos os sexos.

Houve a maior aproximação entre os grupos HM e HT em relação à referência à discriminação sofrida por homossexuais, tendo havido um leve destaque para as mulheres HT.

Em relação à segunda questão, houve uma diferença significativa entre os dois grupos, como mostra a Tabela 2. A principal delas refere-se aos conteúdos que negavam casualidades específicas para a homossexualidade. Os HM, principalmente os homens, deram muito mais estas respostas do que os HT, além de relacionarem a homossexualidade às causas naturais, do tipo nasce-se assim. Os HT, por sua vez, principalmente os homens, concentraram suas respostas em conteúdos que denotam uma intencionalidade quanto à homossexualidade - como ressaltado também na Tabela 1-, influências sociais e visão da homossexualidade como um problema tanto de ordem biológica quanto psicológica.

Mulheres e homens HT, principalmente as primeiras, também tenderam a associar as causas da homossexualidade a uma decepção/não satisfação em relações com pessoas do sexo oposto e à busca por uma realização pessoal e/ou felicidade. Já os HM deram mais respostas colocando a homossexualidade como derivada da interação entre os fatores biológico e social (especialmente os homens), como resultante de uma variabilidade de causas (especialmente as mulheres), além de ressaltarem mais conteúdos referentes ao assumir-se, descobrir-se.

Os homens HM ainda ressaltaram mais as influencias sociais como possíveis causas. Já as mulheres, buscaram dar explicações para a homossexualidade tanto em termos de intencionalidade quanto de não intencionalidade, privilegiando a segunda. Elas também se destacaram em relação aos homens HM, por terem apresentado mais temas apontando como causa da homossexualidade a insatisfação e/ou felicidade. Elas ainda, de forma menos significativa, colocaram a homossexualidade como decorrente de eventos ocorridos durante o desenvolvimento biológico/psicológico do ser humano.

Já entre os HT, homens e mulheres se aproximaram de forma bastante significativa quanto à atribuição de causas

Tabela 2

Freqüências e Percentagens Referentes à Questão sobre as Causas da Homossexualidade

\begin{tabular}{|c|c|c|c|c|c|c|c|c|c|c|c|}
\hline \multirow{2}{*}{ Categorias/grupos } & \multicolumn{2}{|c|}{ homem HM } & \multicolumn{2}{|c|}{ mulher HM } & \multicolumn{2}{|c|}{ homem HT } & \multicolumn{2}{|c|}{ mulher HT } & total HM & \multicolumn{2}{|c|}{ total HT } \\
\hline & $\mathrm{F}$ & $\%$ & $\mathrm{~F}$ & $\%$ & $\mathrm{~F}$ & $\%$ & $\mathrm{~F}$ & $\%$ & $\mathrm{~F} \quad \%$ & $\mathrm{~F}$ & $\%$ \\
\hline Causas naturais & 44 & $\underline{25,1}$ & 14 & 13,8 & 21 & 11,2 & 25 & 12,1 & $58 \underline{21,0}$ & 46 & 11,7 \\
\hline Sem intenção & 20 & 11,4 & 21 & $\underline{20,8}$ & 20 & 10,7 & 40 & $\underline{19,3}$ & 4114,8 & 60 & 15,2 \\
\hline Com intenção & 08 & 4,5 & 11 & $\underline{10,9}$ & 23 & 12,3 & 25 & 12,1 & 196,9 & 48 & 12,2 \\
\hline Influências sociais & 18 & $\underline{10,3}$ & 06 & 5,9 & 41 & $\underline{21,9}$ & 23 & 11,1 & $24 \quad 8,7$ & 64 & $\underline{16,2}$ \\
\hline Negação de causalidade & 45 & $\underline{25,7}$ & 14 & 13,8 & 12 & 6,4 & 16 & 7,7 & $59 \underline{21,4}$ & 28 & 7,1 \\
\hline Assumir/descobrir-se & 13 & 7,4 & 07 & 6,9 & 06 & 3,2 & 12 & $\underline{5,8}$ & $20 \overline{7,2}$ & 18 & 4,5 \\
\hline Biológico + social & 06 & $\underline{3,4}$ & 02 & 2,0 & 03 & $\underline{1,6}$ & 01 & 0,5 & $08 \underline{2,9}$ & 04 & 1,0 \\
\hline Não sei & 04 & 2,3 & 03 & 2,9 & 14 & $\underline{7,5}$ & 06 & 2,9 & 072,5 & 20 & 5,1 \\
\hline $\begin{array}{l}\text { Decepção/não satisfação } \\
\text { com o sexo oposto }\end{array}$ & 02 & 1,1 & 07 & $\underline{6,9}$ & 08 & 4,3 & 17 & $\underline{8,2}$ & 093,2 & 25 & $\underline{6,3}$ \\
\hline $\begin{array}{l}\text { Problemas psicológicos } \\
\text { e/ou biológicos }\end{array}$ & 05 & 2,5 & 02 & 2,0 & 23 & $\underline{12,3}$ & 15 & 7,2 & 072,5 & 38 & $\underline{9,6}$ \\
\hline $\begin{array}{l}\text { Busca de realização } \\
\text { Pessoal }\end{array}$ & 0 & 0 & 05 & $\underline{4,9}$ & 04 & 2,1 & 11 & $\underline{5,3}$ & 051,8 & 15 & $\underline{3,8}$ \\
\hline Várias causas & 06 & 3,4 & 06 & $\underline{5,9}$ & 05 & 2,7 & 07 & 3,4 & $12 \underline{4,3}$ & 12 & 3,0 \\
\hline $\begin{array}{l}\text { Atração pelo proibido/ } \\
\text { protesto }\end{array}$ & 03 & 1,7 & 01 & 1,0 & 03 & 1,6 & 07 & $\underline{3,4}$ & $04 \quad 1,4$ & 10 & 2,5 \\
\hline $\begin{array}{l}\text { Desenvolvimento } \\
\text { psicológico/biológico }\end{array}$ & 01 & 0,5 & 02 & $\underline{2,0}$ & 04 & $\underline{2,1}$ & 02 & 1,0 & 031,9 & 06 & 1,5 \\
\hline
\end{tabular}

Notas: Foram sublinhadas as diferenças mais importantes de percentagens de temas entre os grupos acima de $25 \%$.

$\chi^{2}=35,343, \mathrm{gl}=13, \mathrm{p}<0,0007$ para comparação entre homens e mulheres $\mathrm{HM} ; \chi^{2}=28,782$, gl=13, $\mathrm{p}<0,007$ para comparação entre homens e mulheres HT; $\chi^{2}=73,387, \mathrm{gl}=13, \mathrm{p}<0,0000$ para comparação entre total de HM e HT. 
para a homossexualidade, assim como a negaram causalidades específicas para a mesma. Estes dois aspectos parecem estar relacionados. As mulheres HT tiveram um leve destaque ao ressaltarem a atração pelo proibido/protesto como responsável pela homossexualidade, enquanto os homens mencionaram temas relacionados ao desenvolvimento psicológico e/ou biológico do ser humano e a dizer não saberem o que pode levar alguém a ser um(a) homossexual.

\section{Discussão}

Houve uma diferenciação e uma aproximação entre os grupos pesquisados, mesmo que as representações observadas tenham apresentado alguns conteúdos que parecem contraditórios entre si. Isto pode indicar a relevância do assunto para os grupos, pois parece provocar uma troca/debate, direta ou indireta, entre as representações da homossexualidade, caracterizando as mesmas de formas distintas, porém em torno de aspectos comuns segundo o grupo de orientação sexual e sexo. Nesta direção, quatro aspectos se destacaram: causalidades, reconhecimento social, normatização e discriminação e preconceitos sofridos.

O primeiro deles refere-se às Causalidades: da intenção à não intenção de ser/viver a homossexualidade. A Tabela 1 mostra claramente que os HT destacaram mais o caráter intencional da vivência da homossexualidade, enquanto os HM ressaltaram prioritariamente a não intencionalidade. Observando a Tabela 2 , entre os HM, podemos apontar que a noção de não intencionalidade foi mais proeminente entre os homens, já que estes ressaltaram mais as causas naturais e a negação de casualidade. As mulheres HM, por sua vez, ressaltaram mais aspectos de busca de realização pessoal e decepção com o sexo oposto como possíveis causas da homossexualidade, o que parece indicar uma maior intencionalidade na vivência da mesma. Heider (1970) caracterizou a noção da casualidade pessoal como estando relacionada à noção de intencionalidade. Uma causa é considerada pessoal quando a pessoa é condição necessária e suficiente para a realização de uma ação e quando os meios podem ser variáveis para se alcançar um fim invariável. Desta forma, a intenção que a pessoa tem é fundamental para a realização de uma ação e atribuição de casualidade pessoal sobre a mesma. Sendo assim, a responsabilidade se associa à idéia de intenção e de causalidade pessoal, na medida em que uma pessoa é responsável pela ação que realiza a partir de suas intenções.

Este raciocínio nos faz pensar que os HT podem utilizar a noção de intencionalidade na vivência da homossexualidade como parte da representação da mesma, para assim poder atribuir uma responsabilidade e, talvez, até uma culpa aos próprios homossexuais por sua orientação sexual. Isto poderia dar um respaldo para os próprios HT agredirem e culpabilizarem os HM como desviantes de uma norma, já que este último aspecto também foi muito ressaltado pelos HT. Poderíamos interpretar que os homens HM recorrem a não intencionalidade ou impossibilidade de autocontrole para explicar a homossexualidade como uma forma de justificar e legitimar seu comportamento sexual reprovado socialmente. Nesta direção, ainda podemos apon- $\operatorname{tar}$ (Tabela 2), que os homens HM apresentam mais de $50 \%$ de conteúdo nas categorias de causas naturais e negação de casualidades. Seguindo o raciocínio mencionado anteriormente de associação entre as idéias de causalidade pessoal e responsabilidade, podemos constatar que os homens HM buscam representar a homossexualidade como algo que está fora do controle deles próprios, é algo que é natural e que, no máximo, eles têm a responsabilidade de assumir ou não.

Já os homens HT se concentram, prioritariamente, em três temas de causalidade: as influências sociais gerais; a homossexualidade como problema psicológico e/ou biológico; e os conteúdos com intenção. Isto parece nos indicar duas formas de representar as causas da homossexualidade, que podem atuar de acordo com a situação. Uma, é a tendência já salientada anteriormente, que se refere à intencionalidade atribuída aos homossexuais sobre sua orientação sexual e, outra, que tira a responsabilidade dos homossexuais, porém a associam os problemas e falta. A idéia das influências sociais pode ser interpretada a partir da noção de "problema", a uma forte necessidade de referência à norma e a temas agressivos, como uma possível fonte de influência negativa, que vem de fora, onde o sujeito acaba sendo vítima das relações e ambientes em que viveu - o que ressalta a idéia de disciplinarização dos próprios HT, em que há normas e formas a serem seguidas quanto às relações e estruturas sociais "benéficas". Desenvolveremos melhor este ponto mais adiante.

As mulheres se aproximaram entre si em relação às formas de representar as causas da homossexualidade, como mostrado na Tabela 2. Porém, ambos os grupos evidenciaram uma menor homogeneidade em relação aos homens HT e HM. Uma característica que parece ser comum aos dois grupos de mulheres é a associação da idéia de intencionalidade relacionada à busca de uma realização pessoal, que talvez possa ser derivada de uma possível frustração com pessoas do sexo oposto. Isto parece apontar para uma maior tendência de auto-referência entre as mulheres, em detrimento de referência às normas sociais, como entre os homens HT, ou em fatores externos ao sujeito, como a naturalização, que apareceu entre os homens HM.

Contudo, as mulheres HM apresentaram ainda um outro tipo de representação, mais associado às idéias de não intencionalidade e negação das casualidades, que as aproxima da representação dos homens HM. Porém, nelas não há um forte fator de naturalização, apenas de indefinição e não responsabilidade sobre sua orientação sexual.

Já as mulheres HT, apresentaram, juntamente com a representação citada acima, uma aproximação com os homens HT em relação à disciplinarização dos mesmos, devido à referência acentuada à norma, além de temas que também se referem a uma normalização. Há nelas a noção de que os HM podem ser vítimas de fatores biológicos e/ ou psicológicos, sobre os quais não se tem muito controle, mas também de influências sociais ou de um desejo de ir contra uma convenção que pode e, talvez, deva ser evitado. Porém esta tendência parece ser menos explícita comparada aos homens. 
Em relação às causas da homossexualidade, surgiram em nosso estudo alguns resultados que não apareceram nos estudos citados na primeira parte do texto (Furnham \& Taylor, 1990; Lacerda, Pereira \& Camino, 2002). Desta forma, ampliamos a base de dados sobre este aspecto ao apresentarmos outras causas da homossexualidade apontadas de forma significativa pelos participantes da pesquisa, como as dimensões da não intencionalidade, do tipo desejo e atração, entre outros.

O segundo aspecto foi denominado de Reconhecimento: da esfera pessoal ao âmbito público. O reconhecimento público foi o mais evocado e mostrou-se freqüente em todos os grupos com exceção das mulheres HM.

Entre os HM, o reconhecimento interpessoal foi destacado prioritariamente pelas mulheres. Desta forma, face à maior tendência dos homens em falar do aspecto público, podemos supor que haja diferenças entre os dois grupos na forma que estes têm de assumir sua homossexualidade, de enfrentar os preconceitos e de lutar por seus direitos. Estes dados estão em congruência com os apresentados pelos estudos de Ribeiro e Almeida (2003a, 2003b), que salientaram que os homens denunciam mais a violência sofrida publicamente e são os que mais procuram estratégias de enfrentamento do preconceito, ressaltando uma maior busca de visibilidade pública em relação à apresentada por mulheres HM. Estas, por sua vez, destacaram-se por ressaltar os sofrimentos vividos no âmbito familiar e por buscar mais aceitação neste âmbito. Nesta mesma direção, podemos entender o fato de os homens terem ressaltado mais do que as mulheres os aspectos sócio-morais de grupo e efeitos e vivências negativas. As mulheres, por se restringirem mais ao âmbito interpessoal, possibilitam menos a formação de grupos consolidados e de espaços públicos de socialização das mesmas, o que faz com que tenham menor possibilidade de avaliar e compartilhar, tantos aspectos positivos quanto negativos. Já os homens, por privilegiarem o âmbito público, consolidam mais espaços de socialização entre si, possibilitando haver maior divergência no interior do próprio grupo, fazendo com que certas características não sejam valorizadas por uma parte dele.

De modo geral, o reconhecimento pessoal foi ressaltado mais por homens HM e mulheres HM e HT. Os homens HT parecem não reconhecer este aspecto que está relacionado a conteúdos como orgulho, assumir-se HM, que, associado a uma maior referência a temas agressivos, normatização e referência à discriminação e preconceitos sofridos, nos faz supor que este grupo não consegue representar a vivência da homossexualidade positivamente.

$\mathrm{O}$ terceiro aspecto refere-se à norma como possível forma de disciplinarização. Esta normatização foi ressaltada prioritariamente pelos HT, sobretudo pelos homens, como visto na Tabela 1. Desta forma, este grupo parece ter uma necessidade maior de referir-se e seguir padrões sociais, fazendo com que possam vir a representar a homossexualidade como um comportamento diferente ou que implique maior liberdade. Neste sentido, parecem apontar para uma preocupação com o controle dos padrões sexuais, implican- do em pouco reconhecimento, como dito anteriormente. Isto fica mais evidente se observarmos também os aspectos da afirmação HT e os temas agressivos. Sendo assim, os homossexuais parecem ser reconhecidos, mas de uma forma que atinge a identidade dos HT, provocando a necessidade de uma defesa, na forma de uma não confusão da própria identidade e de uma agressão, que é uma forma de exclusão e de dar menor valor ao grupo diferente e de afirmar o valor de seu próprio. Esta postura pode implicar numa disciplinarização/repressão social da homossexualidade, na medida em que sua vivência deve ser velada ou evitada. E também numa disciplinarização dos próprios HT, numa tentativa de sempre controlar uma possível mudança para o grupo dos HM, marcando sempre um comportamento padrão a ser seguido e um não padrão a ser evitado. Trata-se de confrontos intergrupais cada vez mais explicitados socialmente e que têm repercussões subjetivas para todos os grupos sexuais direta ou indiretamente implicados com a homossexualidade, indicando que o estudo de representações sociais pode ser de grande utilidade para o esclarecimento de alguns desses fenômenos.

A disciplina pode servir como um comportamento exemplar em que são reforçados valores e normas quanto ao que deve ser aceito e valorizado ou não. Desta forma, a grande referência dos HT aos conteúdos de normatização, nos faz pensar que estes podem estar referindo-se a si mesmos e em menor grau aos HM. Como nos diz Durkheim (1895, citado por Aron, 1990), o propósito da punição não é deter o desviante, mas sim satisfazer à consciência/coletividade comum. Já Foucault (1998), ressalta que a vontade de saber fez com que as sexualidades fossem mais faladas, provocando uma maior vigilância e controle sobre as práticas sexuais - o que serve ainda hoje como forma de criar modelos a serem seguidos e/ou evitados, que são reconhecidos apenas como o contraponto desvalorizado.

Quanto aos homossexuais, podemos supor que tenham menos padrões a seguir, sendo-lhes deixadas em aberto possibilidades de criar sua própria forma de ser homossexual - pelo menos até a sua inserção e/ou percepção de um grupo social homossexual -, uma vez que via de regra nascem e crescem em meios (suas famílias) não-homossexuais (Sullivan, 1996). Contudo, no sentido oposto, as normas sexuais heteronormativas irão influenciar este processo, dificultando e/ou retardando a formação de uma identidade que não se restrinja apenas a estas normas. Porém, o processo de disciplinarização pode atuar também dentro dos grupos/comunidades homossexuais, já que foi razoavelmente ressaltada a normatização neste grupo, além dos aspectos sócio-morais de grupo e efeitos sociais e vivências negativas - prevalecendo entre os homens - estabelecendose formas mais aceitáveis ou não de ser/viver a homossexualidade, tanto no âmbito público quanto no privado.

Por último, temos o quarto aspecto que foi denominado de Referência à discriminação e ao preconceito sofrido: sobre vitimização. Este foi bastante evocado por todos os grupos, tendo um leve destaque das mulheres HT (ver Tabela 1). É uma forma geral dos grupos de ter a necessidade de 
denunciar os sofrimentos e as desigualdades sociais. Porém, podemos pensar ainda que este pode ser um discurso baseado nas convenções da sociedade atual, onde não se deve discriminar, mas também onde se sanciona a discriminação negativa de orientações sexuais fora da heterossexualidade. A denúncia não implica numa tomada de ação efetiva. Isto pode ser notado pela constatação da grande evocação dos conteúdos de normatização e de temas agressivos por parte dos HT, o que ressalta a ambivalência do discurso destes últimos. Desta forma, apesar de os HT (especialmente os homens) terem dado muitas respostas referindo-se aos preconceitos/discriminação sofridos pelos HM, parece que ainda é pouco nítida/estruturada entre os mesmos uma representação relacionada a uma postura afirmativa em relação à homossexualidade e/ou que aponte características positivas e concernentes à vivência da mesma fora da esfera da vitimização da desigualdade de direitos sociais.

Os resultados oferecem-nos a oportunidade de refletir melhor a respeito da diversidade sexual no mundo contemporâneo. Consideramos que está havendo transformação sociocultural importante ao nível de contextos de vivência homo e heterossexual em escala e extensão demográfica maiores do que se poderia prever. Nesse sentido, as salas de chat homoeróticos constituem espaços semipúblicos onde a expressão e reestruturação de modelos de sexualidade ao nível simbólico/prático está se realizando, merecendo mais investigações. Ou seja, a facilidade cada vez maior de acesso a grupos que tendiam ao isolamento pode vir a modificar definitivamente uma concepção sexual unificada em torno do binômio heterossexualidade-homossexualidade (Adelman, 2000; Louro, 2001; Watson, 2005). A relação entre teorias sobre gênero e estudos sobre homossexualidade, que é pouco utilizada na literatura nacional (Góis, 2003), poderia ser melhor explorada para auxiliar a compreensão deste processo.

Mesmo assim, parece haver maior lentidão histórica para a dissolução de padrões identitários de sexualidade/gênero ao nível de discurso/argumento verbalizado no espaço público do que comportamento não verbal/imagem a eles associados, sendo estes últimos um campo fértil a ser explorado em futuras pesquisas. Também acreditamos que um modelo que tende puramente à exclusão e punição da homossexualidade deva ter sua aceitação/inserção social diminuída, pelo menos na cultura ocidental, uma vez que há uma tendência de consolidação de democracia e direitos humanos em muitas partes do mundo. Contudo, diante desta emergência de sexualidade relativamente emancipada, é de se esperar reações de defesa da heterossexualidade, assim como revisões de pontos de vista e argumentos justificadores, tornando-se objeto de debate social que deve prolongar-se.

\section{Referências}

Abric, J. C. (2001). O estudo experimental das representações sociais. In D. Jodelet (Ed.), As representações sociais (pp. 155171). Rio de Janeiro, RJ: Editora da Universidade Estadual do Rio de Janeiro.

Adelman, M. (2000). Paradoxos da identidade: A política de orientação sexual no século XX. Revista de Sociologia e Política, 14, 163-171.
Aron, R. (1990). Main currents in sociological thoughts 2. London: Penguin Books.

Bardin, L. (1977). Análise de conteúdo. Lisboa, Portugal: Edições 70.

Foucault, M. (1998). Historia da sexualidade I: A vontade de saber. Rio de Janeiro, RJ: Graal.

Furnham, A., \& Taylor, L. (1990). Lay theories of homosexuality: Aetiology, Behaviours and "cures". British Journal of Social Psychology, 29, 135-147.

Góis, J. B. H. (2003). Desencontros: As relações entre os estudos sobre a homossexualidade e os estudos do gênero no Brasil. Revista Estudos Feministas, 11 (1), 289-297.

Green, J. (2000). Além do carnaval: A homossexualidade masculina no Brasil do século XX. São Paulo, SP: Editora da Universidade Estadual de São Paulo.

Heider, F. (1970). Psicologia das relações interpessoais.. São Paulo, SP: Editora da Universidade de São Paulo.

Hubbard, P. (2001). Sex zones: Intimacy, citizenship and public space. Sexualities, 4(1), 51-71.

Jodelet, D. (1986). La representacion social: Fenomenos, concepto y teoria. In S. Moscovici (Ed.), Psicologia social II (pp. 469494). Barcelona, España: Paidós.

Lacerda, M., Pereira, C., \& Camino, L. (2002). Um estudo sobre as formas de preconceito contra homossexuais na perspectiva das representações sociais. Psicologia: Reflexão e Crítica, 15(1), 165-178.

Louro, G. L. (2001). Teoria Queer: Uma política pós-identitária para a educação. Revistas Estudos Feministas, 9(2), 541-553.

Moscovici, S. (1978). A representação social da Psicanálise. Rio de Janeiro, RJ: Zahar.

Moscovici, S. (2003). Representações sociais: Investigações em Psicologia Social. Petropolis, RJ: Vozes.

Potter, J., \& Litton, I. (1985). Some problems underlying the theory of social representations. British journal of Social Psychology, 24, 81-90.

Ribeiro, A. S. N., \& Almeida, A. M. O. (2003a). Representações sociais da homossexualidade: O que pensam os gays e as lésbicas [Resumo]. In Anais da III Jornada Internacional e I Conferência Brasileira sobre Representações Sociais (pp. 184). Rio de Janeiro, RJ: Editora da Universidade Estadual do Rio de Janeiro.

Ribeiro, A. S. N., \& Almeida, A. M. O. (2003b). Os homossexuais e a busca por visibilidade social. In Anais da III Jornada Internacional e I Conferência Brasileira sobre Representações Sociais (pp. 184). Rio de Janeiro, RJ: Editora da Universidade Estadual do Rio de Janeiro.

Sullivan, A. (1996). Praticamente normal: Uma discussão sobre o homossexualismo. São Paulo, SP: Companhia das Letras.

Trevisan, J. (2000). Devassos no paraíso: A homossexualidade no Brasil, da colônia à atualidade. Rio de Janeiro, RJ: Record.

Watson, K. (2005). Queer Theory. Group AnalY sis, 38(1), $67-81$ 